\title{
PROGRAM PENDAMPINGAN BAHASA INGGRIS UNTUK ANAK AUTIS MENGGUNAKAN BUKU APLIKASI
}

\author{
Yudhi Arifani'1), Nirwanto Ma'ruf'1), Trishna Nanda Barianty'1) \\ 1)Pascasarjana/ Magister Pendidikan Bahasa Inggris, Universitas Muhammadiyah Gresik, Gresik, \\ Jawa Timur , Indonesia \\ Corresponding author: Yudhi Arifani \\ E-mail : yudhi_arif@umg.ac.id
}

Diterima 04 Oktober 2021, Direvisi 22 Oktober 2021, Disetujui 22 Oktober 2021

\begin{abstract}
ABSTRAK
Berkembangnya teknologi pada pembelajaran anak, mengakibatkan orang tua serta guru harus ikut serta dalam perkembangan tersebut demi kemanjuan anak salah satu aplikasi pembelajaran yang bisa digunakan merupakan Our story application yang memungkinkan interaksi orang tua dan anak untuk pembelajaran bahasa inggris. Namun, pendampingan kadang hanya berfokus pada anak-anak normal belum banyak yang melakukan pendampingan bersama dengan anak-anak Autism. Oleh sebab itu, pendampingan ini dilakukan pada anaka-anak Autism Spectrum Disoreder dan orang tua aplikasi pembelajaran bahasa Inggris. terutama dalam pembelajaran reading sebagai bagian terpenting dari keterampilan berbahasa Inggris. Pendampingan ini dilakukan dengan cara berkeliling kerumah setiap peserta yang bersedia setiap minggunya yang mehasilkan adanya faktor pendukung serta faktor penghambat dalam pelaksanaan pendampingan,
\end{abstract}

Kata kunci: membaca; storybook application; ASD; interaksi

\section{ABSTRACT}

The development of technology in children's learning has resulted in parents and teachers having to participate in these developments for the sake of children's progress. One of the learning applications that can be used is Our story application which allows interaction between parents and children for learning English. However, sometimes mentoring only focuses on normal children, not many have assisted with Autism children. Therefore, this assistance is carried out for children with Autism Spectrum Disorder and parents with English learning applications. especially in learning reading as the most important part of English language skills. This assistance is carried out by going around the house of each willing participant every week which results in supporting factors and inhibiting factors in the implementation of mentoring.

Keywords: reading; storybook application; ASD; interaction.

\section{PENDAHULUAN}

Perkembangan teknologi yang terjadi dalam masyarakat berdampak terhadap berbagai aspek kehidupan dan juga pendidikan terutama menggunakan teknologi mobile (Barrot, 2018; Fang et al., 2019; Sadiq et al., 2021). Implementasi pembelajaran menggunakan smartphone telah banyak dilakukan oleh penelitian sebelumnya(Christ et al., 2018; Kucirkova et al., 2015; Neumann, 2020) dari ulasan tersebut menunjukan adanya efektifitas pembelajaran yang bisa didapatkan dengan menggunakan smartphone sebagai media pembelajaran anak. Meskipun media pembelajaran mencangkup seluruh aspek anak namun belum banyak yang melakukan pendampingan penggunaan aplikasi pada anak autism.Gangguan spektrum autisme (ASD) melibatkan gangguan kompleks dalam domain perilaku dan kognitif. Gangguan perilaku meliputi interaksi sosial peserta didik ASD, kesulitan dalam komunikasi, minat terbatas, perilaku berulang, dan bidang kehidupan lainnya (American Psychiatric Association, 2013; Arifani et al., 2021). Karena keterbatasannya dalam pembelajaran serta kemampuannya, program ini kami laksanakan sebagai bentuk pengabdian masyarakat pada orang tua dan anak menggunakan aplikasi storybook. Program pendampingan pembelajaran bahasa Inggris bagianak anak ASD ini merupakan hasil diseminasi kegiatan penelitian penulis tentang bagaimana mengajari anak anak ASD menggunakan aplikasi pembelajaran bahasa Inggris. terutama dalam pembelajaran reading sebagai bagian terpenting dari keterampilan berbahasa Inggris. Dengan perkembangan teknologi yg pesat pembelajaran reading juga mengalami evolusi dari printed reading menjadi electronik reading 
sehingga bagi perlu pendampingan bagaimana agar anak anak ASD yang memiliki keterbatasan cognitive dan komunikasi dapat mengenal teknologi dalam belajar membaca.

Beberapa penelitian sebelumnya telah melakukan implementasi dalam pembelajaran reading menggunakan bahasa inggris mulai dari buku, e-book, dan aplikasi buku(Kucirkova et al., 2015; Neumann, 2020; van de Pol et al., 2010) kebanyakan implementasi dilakukan pada anak-anak native speaker yang notabenenya merupakan anak dengan kemampuan bahasa inggris yang mencukupi, namun belum banyak yang mendampingi anak ASD serta orang tua yang memiliki keterbatasan kosakata. Untuk itu pengabdian ini dilakukan untuk membantu implementasi pembelajaran bahasa inggris terutama di reading skill.

\section{METODE}

Program pendampingan dilakukan pada 10 orang anak ASD yang dilakukan secara berkala implementasi buku aplikasi dilakukan selama 6 bulan dengan cara mengunjungi orang tua dan anak di rumah masing-masing dan melakukan pendampingan bagaimana interaksi orang tua dan anak dengan menggunakan aplikasi buku. Aplikasi yang digunakan merupakan aplikasi yang sudah bisa di download di seluruh Smart Phone android yaitu ourstoy. Aplikasi ini memungkinkan orang tua serta anak membaca cerita serta menulis cerita bersama dengan fitur-fitur touch screen, Box typing, memasukkan gambar dan juga merekam suara. Aplikasi ini telah digunakan pada penelitian sebelumnya (Kucirkova et al., 2015; Kucirkova, Messer, \& Whitelock, 2013; Kucirkova, Messer, Sheehy, et al., 2013) yang merupakan artikel utama yang diikuti. Untuk itu pendampingan ini dilakukan untuk menjawab pendampingan orang tua dan anak ASD dalam penggunaan Story sharing dengan aplikasi Our Story Anakanak Autism. Dalam hal ini tim program pengabdian memilih pendekatan reflektif kolaboratif dengan memberikan penyuluhan secara optimal kepada anak ASD serta orang tuanya. Yang diperinci sebagai berikut:

1. Mengadakan identifikasi permasalahan cara anak ASD dan orang tua berinteraksi dengan book aplikasi

2. Melakukan pendampingan pada orang tua dan anak saat belajar bahasa inggris menggunakan aplikasi buku.

Kegiatan pendampingan ini ini diawali dengan demonstrasi tentang bagaimana menggunakan aplikasi ourbook story sebagai alat pengajaran dan pembelajaran bahasa inggris. Kemudian membimbing secara teknik pada orang tua yang akan menjadi salah satu target pendampingan agar bisa menggunakan aplikasi secara mandiri kegitan ini dilakukan agar dapat mengetahui bagaimana respon para orang tua terhadap permaslahan terhadap penggunaan ourstory book application. Kegiatan pendampingan ini dilakukan secara langsung yaitu melalui tatap muka dengan peserta ataupun secara tidak langsung yaitu melalui media komunikasi whatsapp.Yang selanjutnya nantinya akan melakukan observasi secara langsung pada orang tua dan anak autism.

\section{HASIL DAN PEMBAHASAN}

Pengabdian ini diimplementasikan dalam waktu 6 bulan pada 10 anak ASD yang didamping secara bergantian di berbagai sekolah serta dilakukan secara bergilir di rumah masing-masing. Pendampingan ini dilakukan selama 90 menit dua kali pertemuan dalam satu minggu. Pendampingan ini menunjukan adanya interaksi orang tua dan anak yang menunjukkan beberapa hal sebagai berikut.

\section{a. Partisipasi dan Pelibatan orang tua.}

Dalam pelaksaan program pendampingan orang tua sangat mendukung keterlaksaannya program sehingga memperlancar kegiatan program pendampingan belajar/. Bentuk partisipasi nya antara lain adalah:

lbu mampu memberikan banyak waktu luang untuk melakukan pendampingan bersama didalam rumah meluangkan waktu dengan anak belajar bahasa inggris menggunakan buku aplikasi diluar program pendampingan.

- Ibu mengajak anak untuk tetap antusias dalam pelaksaaan pendampingan penggunaan buku aplikasi selama proses pendampingan. lbu membantu anaknya untuk tetap belajar menggunakan buku aplikasi dan menjaga mood anak mengikuti pendampingan bahkan memberikan reward pada anak jika sang anak berperilaku baik dalam proses pendampingan.

\section{b. Perkembangan anak}

Topik pembelajaran yang dilakukan selama 6 bulan. Pada bulan pertama melakukan observasi pengelanan aplikasi pada orang tua dan anak dengan cara sosialisasi selama 1 bulan dari rumah ke rumah. Kemudian pada bulan kedua melakukan pendampingan implementasi pertama kali pada 10 orang tua dan 
anak di satu lokasi dilakukan secara bergantian karena adanya Covid-19 sehingga perlu melakukan jaga jarak baik pendamping maupun orang tua serta anak. Pada bulan kedua ini ditemukan bahwa anak Autism mengalami banyak kesulitan menggunakan buku aplikasi. Meskipun akan-anak sudah akrab dengan youtube mereka belum akrab dengan aplikasi story book. Sehingga anak mengalami kesulitan dalam memasukkan gambar serta menulis cerita. Pada aplikasi tersebut juga dilengkapi dengan audio record, namun ratarata anak Autism serta orang tuanya tidak menggukan record yang disediakan. 5 dari 10 anak yang didampingi neulis didalam kertas terlebih dahulu sebelum menuliskan di buku aplikasi yang disediakan. Kebanyakan dari mereka takut melakukan kesalahan sehingga mereka memilih menulisnya di kertas lalu menyalinnya di dalam buku aplikasi.

Dalam perkembangannya, anak-anak menggukan kamus digital atau google translate untuk menulis. Hal ini juga membuat terpecahnya konsentrasi anakanak autism karena setelah membuka kamus mereka cenderung membuka youtube guna mengalihkan perhatian dari kebosanan berfikir terjemahan bahasa Indonesia ke bahasa inggris. Hal ini menyebabkan lamanya proses pembelajaran sehingga satu kalimat perlu lebih dari 15 menit untuk menulisnya. Pendampingan memiliki 4 topik berbeda yaitu, kegiatan sehari-hari, buah, liburan, dan kegiatan didalam kelas. Pada Topik pertama tentang buah-buahan. Anak-anak diminta untuk memilih buahbuahan favorit mereka. Lalu memasukkan gambar tersebut kedalam buku aplikasi yang disediakan. Anak-anak memasukkan gambar dibantu dengan ibunya dalam memasukkan gambar itu. kemudian mereka memulai untuk memberi topik yang mereka ingin
Volume 5, Nomor 1, Desember 2021. p-ISSN : 2614-5251 e-ISSN : 2614-526X

tulis. Seperti, tropical fruit yang nantinya diceritakan bahwa tropical fruit adalah buah tropis yang ada di Indonesia adapun anak-anak yang memilih untuk menceritakan anak lain yang memakan buah kesukaannya . pada pendampingan ini ditemukan bahwa anak ASD masih mengalami kesulitan dalam penerjemahan bahasa inggris. Dapat dilihat pada penerjemahan kelengkeng harunya adalah logan bukan kelengkeng. Penulisan kalimat dilakukan secara sederhana hanya terdiri dari subjek, kata kerja dan objek saja tidak menggunakan kalimat kompleks untuk menjelaskan dan menceritakan gambar.
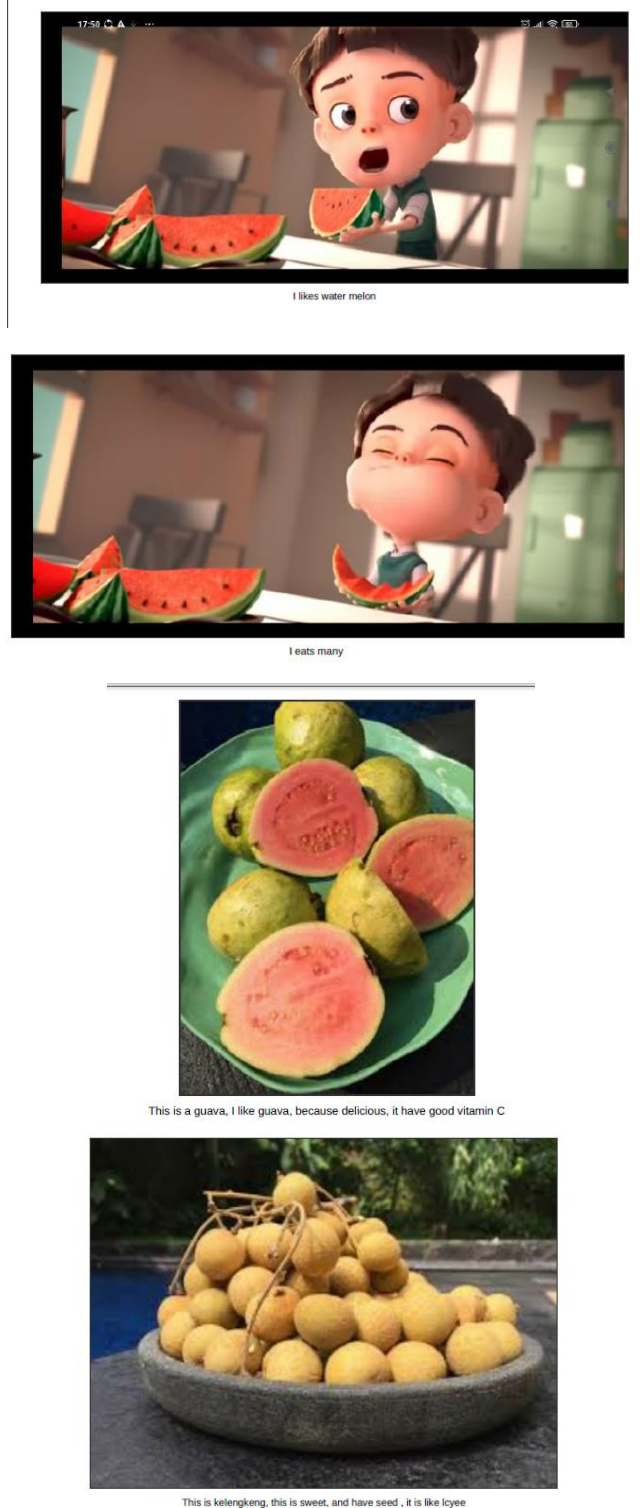

Gambar 1. Storybook application fruit topic 
Pada topik kedua merupakan pengalaman liburan mereka. Anak-anak dan orang tua membuat bersama cerita tentang liburan mereka. Menggunakan gambar yang tersedia dibuku aplikasi sehingga terangkai cerita pengalaman mereka. Dari sini ditemukan bahwa ada kesulitan baik orang tua serta anak dalam penggunakan kata kerja yang tepat pada pengalaman berlibur. Pada struktur penulisan orang tua masih mengarahkan ke pada pola grammar present menggunakan kata kerja bentuk pertama ketimbang kata kerja bentuk kedua. Seperti "I go to beach" yang seharusnya adalah "I went to beach"

Perseta didik mampu mengelolah kosakata bahasa inggris dan juga mampu membuat kalimat bersama dengan short grammatical yang terdiri dari subject, verb dan object contohny adalah "Juna plays soccer ball" atau "He wakes up in the morning". Hal ini juga terjadi pada topic activity in classroom yang ditulis merupakan kalimat-kalimat yang cukup singkat seperti "There are many tables and Chairs" lalu "There is a map in classroom" yang sebenarnya bukan kalimat bercerita yang seharusnya ditulis. Melalui program ini anak bisa mengimplementasikan dan juga mengkoneksikan kosakata bahasa inggris pada kegiatan sehari-hari dan menginat kegiatan yang dilakukan. Pronoucation dari anak tersebut juga mengalami kesulitan pronounciation seperti dalam membaca "Eat " namuan orang tua dan anak membacanya "Ate" anak Autis melakukannya secaraberulang namun,masih belum bisa seusai dengan pronounce yang benar. Selain itu, masih ada kesalahan penulisan yang terjadi meskipun sudah melakukan review bersama antara orang tua dan anak.
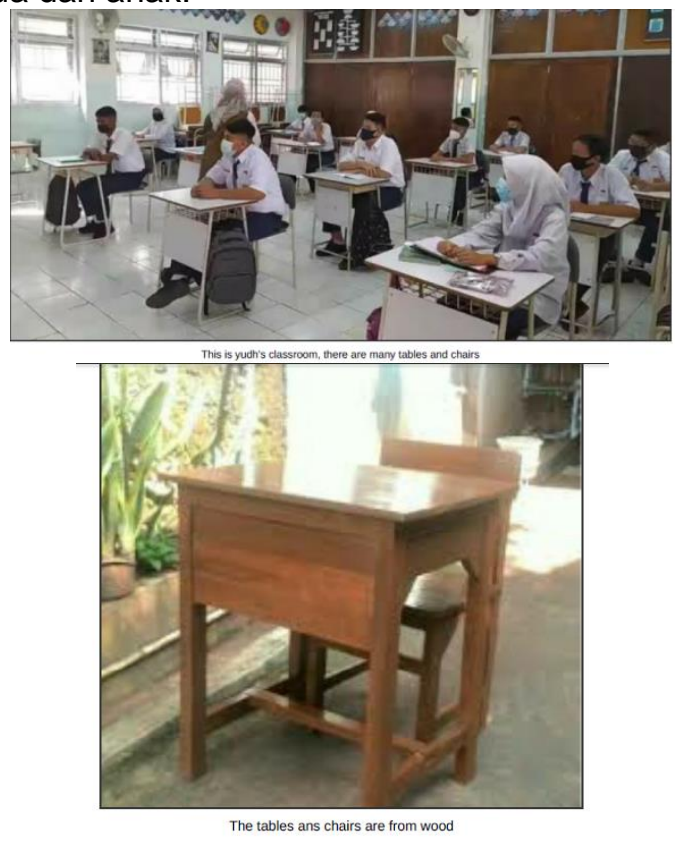

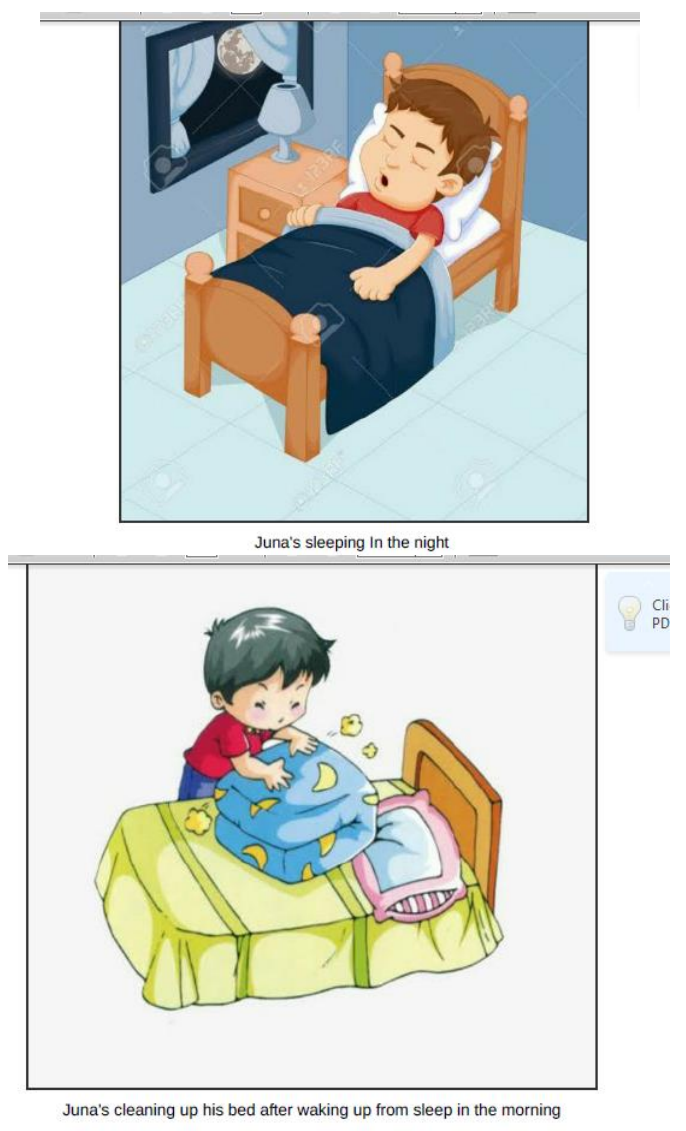

Gambar 2. Hasil cerita menggunakan story book application

Pada gambar-gambar tersebut menunjukan berbagai perkembangan penulisan ide cerita anak dan orang tua selama menggunakan aplikasi ourstory. Terlihat bagaimana perbedaan murid dalam membuat kalimat dan cerita dalam bahasa inggris.

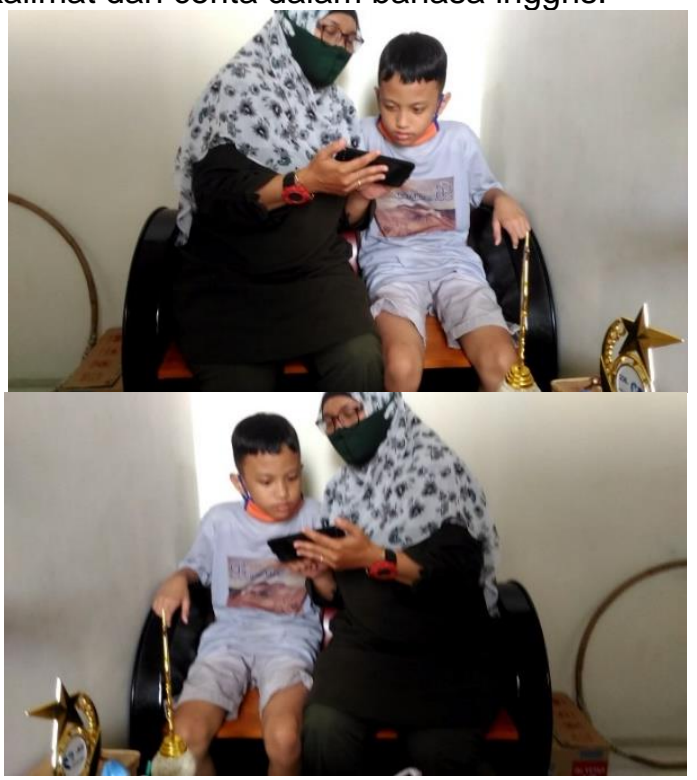

Gambar 3. Orang tua dan anak memakai storybook application bersama 
c. Faktor Pendukung dan Penghambat

Faktor pendukung

- Kerjasama antara orang tua dan anak erjadi saat proses interaksi bersama membuat cerita bersama dan menulis cerita didalam buku aplikasi. Hal ini ditunjukan dari bagaimana anak Autism dan juga orang tua.

- Motivasi belajar anak meningkat, terlihat dari antusiasme anak dalam membuat cerita didalam aplikasi mobile phone yang penuh gambar dan juga fiture menarik

- Penambahan kosakat yang terjadi pada anak secara tidak langsung mereka belajar melalui menerjemahkan menggunakan kamus dan juga menulis didalam kalimat.

Faktor Penghambat

- Seringnya terjadi distraksi antara anak dengan aplikasi yang ada karena dipasang di mobile phone, anak-anak cenderung ingin memegangnya dan mencari youtube untuk diakses.

- Penggunaannya cukup mudah bagi yang sudah terbiasa menggunakan smart phone namun tidak bagi anak-anak Autism yang masih belum bisa mengontrol diri secara emosionalnya, sering kali tidak sabar dalam memencet tombol touch screen.

\section{SIMPULAN}

Melalui program pendampingan ini yang diikuti oleh 10 pasang orang tua dan anak selama 6 bulan dari 14 juli hingga 14 desember 2020, agar program diselenggarakan dengan lancar maka pendampingan dilakukan dalam rumah setiap anak dan orang tua setiap harinya. Peserta menikmati proses pembelajaran dan mampu menyelesaikan pertanyaan-pertanyaan ketika bekerja secara individu. Selama kegiatan, masyarakat cukup merespon dan menyambut dengan hangat dengan adanya dukungan dan membantu jalannya semua program rencana kegiatan yang sudah dilaksanakan. Pada kegiatan selanjutnya perlu adanya perhatian khusus yang bisa diterapkan pada guru anak Autism.

\section{DAFTAR RUJUKAN}

American Psychiatric Association. (2013). Diagnostic and Statistical Manual of Mental Disorders, 5 ed. In American Psychiatric Association.

Arifani, Y., Barianty, T. N., \& Paulina. (2021). EFL learners' cognition process: A case study of two ASD learners with different IQ levels. The Journal of ASIA TEFL, 18(2), 657-665.

Barrot, J. S. (2018). Facebook as a learning environment for language teaching and learning: A critical analysis of the literature from 2010 to 2017. Journal of Computer Assisted Learning, 34(6), 863-875. https://doi.org/10.1111/jcal.12295

Christ, T., Wang, X. C., \& Erdemir, E. (2018). Young children's buddy reading with multimodal app books: reading patterns and characteristics of readers, texts, and contexts. Early Child Development and Care, 188(8), 1012-1030. https://doi.org/10.1080/03004430.2016.1 241776

Fang, J. W., Hwang, G. J., \& Chang, C. Y. (2019). Advancement and the foci of investigation of MOOCs and open online courses for language learning: a review of journal publications from 2009 to 2018. Interactive Learning Environments, $O(0)$, $1-19$.

https://doi.org/10.1080/10494820.2019.1 703011

Kucirkova, N., Messer, D., Sheehy, K., \& Flewitt, R. (2013). Sharing personalised stories on iPads: A close look at one parent-child interaction. Literacy, 47(3), 115-122. https://doi.org/10.1111/lit.12003

Kucirkova, N., Messer, D., \& Whitelock, D. (2013). Parents reading with their toddlers: The role of personalization in book engagement. Journal of Early Childhood Literacy, 13(4), 445-470. https://doi.org/10.1177/14687984124380 68

Kucirkova, N., Sheehy, K., \& Messer, D. (2015). A Vygotskian perspective on parent-child talk during iPad story sharing. Journal of Research in Reading, 38(4), 428-441. https://doi.org/10.1111/1467-9817.12030

Neumann, M. M. (2020). Teacher Scaffolding of Preschoolers' Shared Reading With a Storybook App and a Printed Book. Journal of Research in Childhood Education, 34(3), 367-384. https://doi.org/10.1080/02568543.2019.1 705447

Sadiq, R. B., Cavus, N., \& Ibrahim, D. (2021). Mobile application based on $\mathrm{CCl}$ standards to help children learn English as 
a foreign language. Interactive Learning Environments, 29(3), 442-457. https://doi.org/10.1080/10494820.2019.1 579239

van de Pol, J., Volman, M., \& Beishuizen, J. (2010). Scaffolding in teacher-student interaction: A decade of research. Educational Psychology Review, 22(3), 271-296. https://doi.org/10.1007/s10648010-9127-6 